\title{
Comparing Student Performance, Attitudes and Preferences in an Introduction to Business Course: Online, Hybrid and Traditional Delivery Methods - Who Makes the "A" Grade?
}

\author{
Daniel Gutierrez, (E-mail: dgutierrez@valenciacc.edu) Valencia Community College, Orlando \\ Storm Russo, (E-mail: srusso@valenciacc.edu) Valencia Community College, Orlando
}

\begin{abstract}
The present study compares three Introduction to Business courses delivered using three different teaching formats; online, hybrid and traditional methods. Findings indicate that while the traditional course received higher ratings by students, hybrid students outperformed students in the online and traditional course $(n=56)$. Thirty-five percent of the students in the hybrid course earned an " $A$ " compared to 23 percent of the traditional students, while only 7 percent of the students enrolled in the online course completed the course with an "A" grade. Student attitudes also indicate once a student experiences a hybrid model course, there is strong preference for this type of delivery method. Although 85 percent of the students enrolled in the hybrid course had never enrolled in a distance learning course, 73 percent selected the hybrid format as their preference of delivery method. Strong support exists indicating that hybrid courses that are well designed create an atmosphere that increase student learning. Moreover, once students have a "good hybrid experience", they are more likely to prefer courses designed as hybrids.
\end{abstract}

Introduction

plethora of research exists comparing the performance of online classes to traditional classes
(see Beare, 1989; Martin and Rainey, 1993; McCleary and Egan, 1989; Neushauser, 2002;
Veruin and Clark, 1991 just to name a few) with little differences between student experiences being reported. Others however (Bartlett, 1997; Bothun, 1998; Heines and Hulse, 1996; Kabat and Friedel, 1990; Schutte, 1996), argue that students perform better in distance courses versus traditional courses. One area however, in distance learning delivery formats and student performance that has produced little research is the hybrid or blended model (Gutierrez, 2004; Gutierrez, Wiese, Lopez, Portello, and Beninati, 2004). Some may consider this ironic, since hybrid courses have been touted as being the wave of the future in distance learning (Gutierrez, 2004; Gutierrez, Wiese, Lopez, Portello, and Beninati, 2004; Young, 2002). 
The present study attempts to address this deficiency in the literature by examining and comparing student performance in three Introduction to Business courses taught using three different delivery formats. The comparison includes an online course; a hybrid course, and a course taught using traditional methods (lecture). The study focuses on three primary research questions. First, which group, if any, performed better than the other groups? Second, how do students ratings of these courses vary by delivery format? And third, what type of delivery format do students enrolled in these courses prefer?

\section{Literature Review}

The literature concerning distance learning is replete with studies that compare traditional courses with online courses (Gutierrez, 2004; Gutierrez, Wiese, Lopez, Portello, and Beninati, 2004). Past studies however, have concentrated on comparisons between traditional and online courses (Beare, 1989; Martin and Rainey, 1993; McCleary and Egan, 1989; Neushauser, 2002; Veruin and Clark, 1991). The latest distance learning trend that seems to be sweeping colleges across the U.S. however is hybrid or blended courses. These courses combine the best of both world (Young, 2000) but have received little attention in terms of research (Gutierrez, 2004; Gutierrez, Wiese, Lopez, Portello, and Beninati, 2004). As such, our focus here concentrates on the literature that addresses the hybrid model.

A review of the literature by Gutierrez (2004) discovered less than a dozen articles addressing the concept, design and assessment of hybrid courses. Studies that do address hybrid models from this perspective include Lago, (2000); Leh (2002); Rivera and Rice (2002); Gutierrez, (2004); and Gutierrez, Wiese, Lopez, Portello, and Beninati, (2004). One reason why such a paucity of literature exists is that hybrid courses are relatively new to the academic arena (Gutierrez, 2004; Gutierrez, Wiese, Lopez, Portello, and Beninati, 2004; Young, 2002).

According to Lago (2000), one of the most extensive and ambitious research projects concerning hybrid courses is being conducted by the University of Central Florida's Research Initiative for Teaching Effectiveness (RITE). According to RITE, students enrolled in hybrid courses have experienced higher success and lower withdrawal rates compared to traditional and online students.

In a study of graduate courses, Leh (2002) found that students favor the hybrid model over the traditional model because they felt they learned more in the hybrid setting. Leh's study however, is severely hampered by the fact that most of her students were teachers, which are not typical students that represent the general student body (Gutierrez, 2004).

Rivera and Rice (2002) compared student performance, satisfaction and instructor experiences between traditional, hybrid and online courses. While students in the hybrid course indicated they were more satisfied with the delivery method, no differences in student performances were found. Moreover, the findings are problematic because outcome measures were different for the three groups. Only the hybrid and online courses used the same outcomes as measures in the course.

Two most recent studies involving the assessment of hybrid courses include studies conducted by Gutierrez, (2004); and Gutierrez, Wiese, Lopez, Portello, and Beninati, (2004). Gutierrez (2004) compared two criminology classes and found that overall, students performed better in the hybrid course versus those enrolled in a traditional criminology course. The comparison however, only included a hybrid and traditional course and did not include comparisons to an online course. Gutierrez, Wiese, Lopez, Portello, and Beninati, (2004) assessed hybrid courses across three different disciplines including business, accounting and criminal justice. Findings indicate that only the students enrolled in criminal 
justice classes preferred hybrid courses over other delivery formats. Their study however, failed to compare any other type of delivery formats other than just the hybrid model and they did not examine course outcomes.

\section{Methods}

This study examines three Introduction to Business courses taught at a community college located in the southeastern region of the Unites States. All classes were ten week courses offered during the summer semester of 2004. Each course was delivered via different delivery formats. One course was delivered completely online, the second was delivered as a blended or hybrid course and the third was delivered using traditional methods which incorporated technology in the classroom. All three classes were taught by the same instructor.

Course outcomes in each class were identical. The same text was used in each course. Each student was required to complete seven quizzes, a midterm exam, a final exam and research paper concerning a Fortune 500 company. The quizzes comprised 40 percent of the final grade, the midterm and final exams 20 percent each, and the term paper accounted for the remaining 20 percent of the course grade.

A survey instrument designed to probe the areas of interest was developed and distributed to all three classes. Students were asked to voluntarily complete the survey and return them to the instructor. Students who did not complete the course because they withdrew from the course, stopped attending or were withdrawn from the course by the instructor were not included in the study. A total of 51 students were surveyed, 13 from the online class, 18 from the hybrid class, and 20 from the traditional class. The survey instrument developed asked students to rate the following areas on a scale of one to ten as they pertained to the course: 1) the instructor's computer skills, 2) instructor's level of communication and feedback during the course, 3) how well the course was organized, 4) how much students thought they learned in the course, 5) the academic standards in the class, and 6) the students' overall learning experience in the class. Mean scores were then calculated for each rating and all scores were converted to a percentage grade based on 100 percent. Ratings between 9 and 10 represent 90 to 100 percent, or an "A". Scores between 8 and 8.9 represent a "B" (or 80 to 89 percent) and so on. Students were also asked how relevant they thought course assignments, lectures and exams were in relation to the course. Finally, students were also asked if given the preference, what type of course would they rather be enrolled in; traditional, online or hybrid courses. We also collected basic demographic data about the students as well as other information concerning the students we felt were important and could be factors that may influence

\section{Findings}

We begin by first describing the students' past experiences with distance learning courses, discuss their preferences and present the finding on how students rated the courses and the professor and conclude with how students from each group performed.

Regarding previous experience with distance learning courses, 76 percent of the entire sample indicated they had never taken a distance learning course before the start of the semester. When we examined this course by course, we found profound differences in student experiences with distance learning. 62 percent of the students enrolled in the online course indicated they had taken a distance learning course in the past. Conversely however, 85 percent of the students in the hybrid course indicated they had never taken a distance learning course, while an even greater number of traditional students, 94 
percent, indicated they had no experience with distance learning courses. In terms of preference, when asked if given a choice which type of course they would prefer, the hybrid students overwhelming indicated that they would prefer to take class delivered via hybrid format than an online or a traditional course. 73 percent of the students enrolled in the hybrid selected the hybrid delivery format as the format of their choice. The online students indicated they preferred either an online or a hybrid course over a course delivered via traditional methods. 36 percent of the online students preferred online, 36 percent hybrid and the remaining 28 percent preferred traditional courses. The traditional group who had the least experience with distance learning courses, selected traditional courses as their preference. 75 percent of the traditional students selected traditional courses as their preference.

When we examined how students rated the course and the professor, the traditional students gave the highest ratings to all six areas we asked them to evaluate. Overall, the traditional course received the highest ratings by students. The online and hybrid courses received identical or almost identical ratings in four of the six areas. The highest ratings by all three groups was in two categories, how well the course was organized and the instructor's level of communication with the students during the course of the semester.

Table 1. How Students Graded The Course \& The Professor

\begin{tabular}{|l|c|c|c|}
\hline \multicolumn{1}{|c|}{ Graded Course Items } & $\begin{array}{c}\text { Traditional } \\
\text { Course }\end{array}$ & $\begin{array}{c}\text { Online } \\
\text { Course }\end{array}$ & $\begin{array}{c}\text { Hybrid } \\
\text { Course }\end{array}$ \\
\hline 1) Instructor's Computer Skills & $95 \%$ & $88 \%$ & $89 \%$ \\
\hline 2) Instructor's Communication Level & $97 \%$ & $89 \%$ & $94 \%$ \\
\hline 3) How Well Course Was Organized & $97 \%$ & $91 \%$ & $89 \%$ \\
\hline 4) How Much Students Learned & $89 \%$ & $84 \%$ & $85 \%$ \\
\hline 5) Academic Standard For The Course & $92 \%$ & $84 \%$ & $83 \%$ \\
\hline 6) Overall Student Learning Experience & $92 \%$ & $87 \%$ & $87 \%$ \\
\hline 7) Overall Student Rating & $93.6 \%$ & $87.2 \%$ & $87.8 \%$ \\
\hline
\end{tabular}

At the start of the semester class rankings by the groups' respective GPA was as follows. The online group had the highest GPA at 3.39, followed by the traditional group with a GPA of 3.13 with the hybrid group having the lowest GPA at 2.97. Conversely however, final course grades indicate that the hybrid students performed slightly better than the traditional or online students. The mean score for the hybrid group was 83.75 percent (SD 10.3), 82.76 percent (SD 6.7) for the traditional group and 82 percent (SD 7.8). for the online group. When we examined the number of " $A$ " grades achieved by each group, a substantial difference in regards to the percentage of students in each course that did earn an " $A$ " as a final grade was found. The hybrid group had the highest number of " $A$ " grades at the end of the course and the online class had the lowest. 35 percent of the hybrid students earned an " $A$ " in the course, 26 percent of the traditional students earned an " $A$ ", and only 7 percent of the online students earned an " $A$ " at the conclusion of the course. 


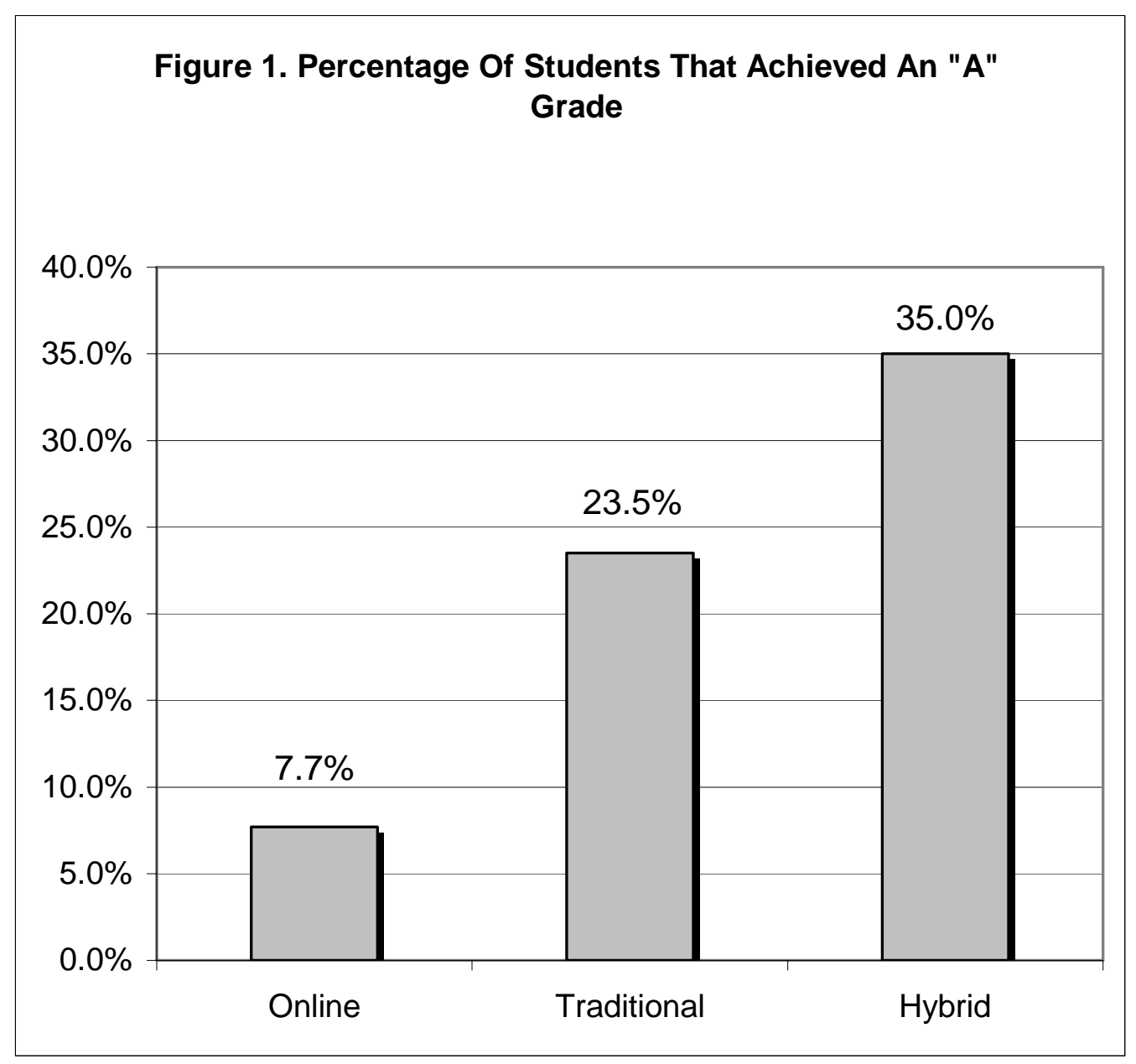

\section{Discussion/Limitation}

We have examined three Introduction to Business courses delivered via different formats; traditional, online and hybrid. Our findings indicate that the student in hybrid course performed better than students taught using different delivery formats. Before the start of the class the hybrid group had the lowest GPA, while the online group had the highest GPA of the three groups. Upon completion of the course, hybrid students had achieved higher GPA score for the course than any other group. The online group achieved the lowest GPA score and the traditional group's scores remained in-between the other two groups. Concerning the number of students that achieved an "A" grade in the course, the hybrid group achieved a substantially higher percentage of " $A$ " grades than any other group. 35 percent of the hybrid students earned an " $\mathrm{A}$ " while only 23.5 percent and 7.7 percent of the traditional and online students, respectively, earned an "A".

While the hybrid class performed better than the other two sections, students gave it some of the lowest ratings in several areas including course organization, academic standards, and overall student learning experiences. The traditional course on the other hand, received the highest ratings in all areas. Only one area, the instructor's level of communication received a 90 percent or higher rating. In spite of receiving lower ratings than the traditional course, once students had an opportunity to experience a 
course delivered using the hybrid model, 73 percent of them selected the hybrid model as their preference over traditional or online courses.

In light of these facts, a word of caution is necessary. First, while three different delivery formats were examined, the sample is small and caution should taken not generalize these finding to the general student. Second, only one type of business course has been examined, which may be problematic. Not all courses may be compatible with the hybrid model, depending on the course content and subject matter to be taught. Finally, other salient factors may at work that can provide explanation as why the hybrid students outperformed the other groups. Regardless, if hybrids are to be seriously considered a viable delivery format and perhaps the wave of the future as suggested by Gutierrez, (2004); and Gutierrez, Wiese, Lopez, Portello, and Beninati, (2004); and Young (2002), more research should be forthcoming in this areas. Additional research may also provide or at least begin to provide information that can used to build a hybrid model. This model could be used to guide the design and implementation of hybrid courses.

\section{References}

Bartlett, T. (1997). The Hottest Campus on the Internet. Business Week, 77-80.

Beare, P. L. (1989). The Comparative Effectiveness of Videotape, audiotape, and telecture. The American Journal of Distance Education, 3, 2, 57-66.

Bothun, G. D. (1998). Distance Education: Effective Learning or Content-free Credits? Cause/Effect, 21, 2, 28-37.

Gutierrez, D. (2004). A comparative study between a traditionally taught criminology course and a computer hybrid course: Does technology in the classroom make a difference? Journal of College Teaching and Learning, 1, 3, 59-64.

Gutierrez, D., Wiese, J., Lopez, N., Portello, N. and Beninati, A. (2004). Student perceptions of computer hybrid courses across three disciplines: What students think about hybrid courses and what type of delivery format they prefer. Journal of College Teaching and Learning, 1, 8, 1-6.

Heines, R. A., and Hulse, D. B. (1996). Two-way Interactive Television. The American Journal of Distance Education, 3, 1, 50-60.

Kabat, E. J., and Friedel, J. (1990). The Development, Pilot-testing, and Dissemination of a Comprehensive Evaluation Model for Assessing the Effectiveness of a Two-way Interactive Distance Learning System. Davenport, Iowa: Eastern Iowa Community College. (ERIC Document Reproduction Service No. ED 332 690).

Lago, M. E. (November 2000). The Hybrid Experience: How Sweet It Is! Converge Magazine. Retrieved October 10, 2003 from http://www.convergemag.com/ Publications/CNVGNov00/hybrid/index.shtm

Leh, A. S. (2002). Action Research on Hybrid Courses and their Online Communities. International Council for Education Media, 31-38. 
Martin, E. E., and Rainey, L. (1993). Student Achievement and Attitude in a Satellite-delivered High School Science Class. The American Journal of Distance Education, 7, 1, 54-61.

McCleary, I. D., and Egan, M. W. (1989). Program Design and Evaluation: Two-way Interactive Television. The American Journal of Distance Education, 3, 1, 50-60.

Neuhauser, C. (2002). Learning Styles and Effectiveness of Online and Face-to-Face Instruction. The American Journal of Distance Education, 16, 2, 99-113.

Rivera, J. C., and Rice, M. L. (2002). A Comparison of Student Outcomes \& Satisfaction Between Traditional \& Wen Based Course Offerings. Online Journal of Distance Learning Administration, Vol. V, 3, Fall 2002. Retrieved October 5, 2003 from http://www.westga.edu/ distance/ojdla/fall53/rivera53.html

Souder, W. E. (1993). The Effectiveness of Traditional vs. Satellite Delivery in Three Management of Technology Master’s Degree Programs. The American Journal of Distance Learning, 7, 1, 37-53.

Veruin, J. R., and Clark, T. (1991). The Foundations of Effective Practice. San Francisco: Jossey-Bass.

Young, J. R. (22, March 2002). Hybrid Teaching Seeks to End the Divide Between Traditional and Online Instruction. Chronicle of Higher Education, Vol. 48, 28, A33-1c. Retrieved October 5, 2003 from http://chronicle.com/free/v48/ 
